\title{
POLÍTICAS INCLUSIVAS PARA PESSOAS COM DEFICIÊNCIA NO BRASIL
}

http://dx.doi.org/10.5902/2318133834984

\author{
Cristian Evandro Sehnem ${ }^{1}$ \\ Silvia Maria de Oliveira Pavão²
}

\begin{abstract}
Resumo
Neste texto de revisão de literatura tem-se por objetivo apresentar conceitos e princípios fundamentais das políticas inclusivas para as pessoas com deficiência. São comuns os preconceitos e desentendimentos acerca das políticas de inclusão destinadas as pessoas com deficiência. As políticas públicas de acessibilidade, de tecnologia assistiva e de ação afirmativa têm papel crucial na transformação da sociedade e precisam ser o quanto antes conhecidas e disseminadas. Conclui-se que a ênfase dada ao aprendizado e prática inclusivos a partir do segmento educacional é tida como o mais eficiente e democrático caminho para a inclusão educacional.
\end{abstract}

Palavras-chave: políticas inclusivas; pessoas com deficiência; acessibilidade educacional.

\section{INCLUSIVE POLICIES FOR PEOPLE WITH DISABILITIES IN BRAZIL}

\section{Abstract}

This article of literature review aims to present fundamental concepts and principles of inclusive policies for people with disabilities. Prejudice and misunderstanding about inclusion policies for people with disabilities are common. Public policies for accessibility, assistive technology and affirmative action play a crucial role in the transformation of society and must be known and disseminated as soon as possible. It is concluded that the emphasis on inclusive learning and practice from the educational segment is seen as the most efficient and democratic pathway to educational inclusion.

Key-words: inclusive policies; disabled people; educational accessibility.

\footnotetext{
${ }^{1}$ Universidade Federal de Santa Maria, Brasil. E-mail: cristiansehnem@gmail.com.

${ }^{2}$ Universidade Federal de Santa Maria, Brasil. E-mail: silviamariapavao@gmail.com.
} 


\section{Introdução}

o decreto federal n. 9.203/2017, que "dispões sobre a política de governança da administração pública federal direta, autárquica e fundacional", encontrase a definição de governança pública como um "conjunto de mecanismos de liderança, estratégia e controle postos em prática para avaliar, direcionar e monitorar a gestão, com vistas à condução de políticas públicas e à prestação de serviços de interesse da sociedade" (Brasil, 2017, art. $2^{\circ}$ ).

As políticas públicas, de acordo com Brankaleon; Yamanaka; Castro (2015), se configuram como programas públicos, projetos, leis, campanhas publicitárias, esclarecimentos públicos, inovações tecnológicas e organizacionais, subsídios governamentais, rotinas administrativas, decisões judiciais, coordenação em rede atores, gasto público direto, contratos com stakeholders dentre outros. Para tanto, foi instituído o cargo e carreira de especialista em políticas públicas e gestão governamental, com vistas a "execução de atividades de formulação, implementação e avaliação de políticas públicas, bem assim de direção e assessoramento em escalões superiores da administração direta e autárquica" (Brasil, 1989, art. 1ํ). Uma política pública é um modo e meio pelo qual são organizadas, realizadas e controladas as ações públicas e sociais.

Neste artigo de revisão de literatura, tem-se por objetivo apresentar conceitos e princípios fundamentais das políticas inclusivas para as pessoas com deficiência. É um estudo que apresenta relevância do ponto de vista social, considerando que existe um manancial de documentações legais (Brasil, 2011, 2015, 2016, 2017) que regulamentam as práticas às pessoas com deficiência.

\section{Inclusão social das pessoas com deficiência}

Na portaria n. 1.060/2002, do Ministério da Saúde, que trata da política nacional de saúde das pessoas com deficiência, "encontra-se um completo e abrangente conceito para uma política pública tardia, mas crescente no país, nomeada inclusão social" (Sassaki, 2007, p. 3):

$\mathrm{Na}$ raiz dessa nova abordagem está a perspectiva da inclusão social, entendida como o processo pelo qual a sociedade se adapta para incluir, em seus sistemas sociais gerais, pessoas com necessidades especiais e, simultaneamente, estas se preparam para assumir seus papéis na sociedade. A inclusão social constitui, então, um processo bilateral no qual as pessoas, ainda excluídas, e a sociedade buscam, em parceria, equacionar problemas, decidir sobre soluções e efetivar a equiparação de oportunidades para todos. (Brasil, 2002, s/p)

A presença das pessoas com deficiência em todos os segmentos e espaços da sociedade não é apenas de sua (de sua o que??? Incompreensível), mas de todos que a compõem. Tanto é fato que a concepção anterior desta política, denominada integração social, em que à pessoa com deficiência bastaria esforçar-se para buscar espaços e interações sociais para viver e ser bem-sucedida como outra qualquer:

A prática da inclusão social vem aos poucos substituindo a prática da integração social, e parte do princípio de que, para inserir todas as pessoas, a sociedade deve ser modificada de modo a atender as necessidades de todos os seus membros: uma sociedade inclusiva não 
admite preconceitos, discriminações, barreiras sociais, culturais e pessoais. Nesse sentido, a inclusão social das pessoas com deficiências significa possibilitar a elas, respeitando as necessidades próprias da sua condição, o acesso aos serviços públicos, aos bens culturais e aos produtos decorrentes do avanço social, político, econômico e tecnológico da sociedade. (Brasil, 2002, s/p)

A partir da inclusão, o contato e convívio com as pessoas que possuem deficiência questionam teorias e práticas por vezes consagradas ao longo dos séculos, ao usarem e apresentarem formas alternativas de viver e conviver socialmente. Não que estudos e reflexões nesse sentido não tenham acontecido antes, mas, com a possibilidade desse público adentrar e conviver na sociedade, como nas instituições de ensino superior por exemplo, junto aos demais estudantes, o que lhes era limitado em tempos anteriores, gerou maior visibilidade de suas limitações e potencialidades:

Desse modo, o modelo social defendido pelo Movimento das Pessoas com Deficiência é o grande avanço das últimas décadas. Nele, a interação entre a deficiência e o modo como a sociedade está organizada é que condiciona a funcionalidade, as dificuldades, as limitações e a exclusão das pessoas. (Lanna Júnior, 2010, p. 69)

Com isso, tem-se gerado novas concepções quanto ao potencial humano, associadas a perspectivas inclusivas, com vantagens para toda a sociedade. De modo mais específico a pesquisa, o desenvolvimento e o uso de recursos de acessibilidade, que, além de permitir a autonomia e independência de pessoas com limitações sensoriais, físicas ou intelectuais, também disponibilizam facilidades, confortos e novas opções à população em geral. A política pública da acessibilidade visa, justamente, a equalizar as impossibilidades sociais enfrentadas pelas pessoas com deficiência, de modo que, em um futuro quiçá próximo, ações afirmativas como as reservas de vagas e isenções de impostos sejam desnecessárias.

\section{Acessibilidade, tecnologia assistiva e ações afirmativas}

A acessibilidade pode ser considerada a principal política pública que visa a eliminar as barreiras sociais que impedem o ir e vir de todos:

Acessibilidade: possibilidade e condição de alcance para utilização, com segurança e autonomia, de espaços, mobiliários, equipamentos urbanos, edificações, transportes, informação e comunicação, inclusive seus sistemas e tecnologias, bem como de outros serviços e instalações abertos ao público, de uso público ou privados de uso coletivo, tanto na zona urbana como na rural, por pessoa com deficiência ou com mobilidade reduzida. (Brasil, 2015, art. 3ํㅜ)

Porém, o envolvimento social necessário e instigado pelas instituições representativas de pessoas com deficiência para a acessibilidade é um desafio de tamanha importância. Se cada uma e todas as pessoas não aplicarem a acessibilidade em seus trabalhos, nos serviços que prestam, nas formas pelas quais se comunicam, nos modos como entendem que se deve estudar e apreender novos conhecimentos, que se deve usar os recursos e produtos públicos e mesmo privados, que se deve agir e interagir socialmente e daí por diante, a efetiva e real inclusão dessa parcela da população, com 
autonomia, independência, segurança e dignidade, não se tornará real. E, infelizmente, ainda depara-se com a maioria dos prédios, livros, ônibus, programas televisivos, sites, planos de aula, recursos pedagógicos, slides, eventos, calçadas, máquinas de autoatendimento, roupas, embalagens, cartões magnéticos e muitos outros recursos e produtos, que deveriam estar disponíveis e usáveis por todos, completamente inacessíveis. Por isso, uma série de leis, normas, guias e demais documentos legais e públicos dizem respeito à acessibilidade e demonstra sua amplitude, importância, avanços já conquistados e que ainda precisam ser trilhados.

Então, no mesmo viés e com o intuito de atender às especificidades da pessoa com deficiência, em sua individualidade, mais exatamente nas situações em que as acessibilidades são insuficientes para permitir a autonomia e independência, recorre-se à tecnologia assistiva. Na Lei Brasileira de Inclusão da Pessoa com Deficiência (Brasil, 2015, art. $3^{\circ}$ ), tecnologia assistiva são

produtos, equipamentos, dispositivos, recursos, metodologias, estratégias, práticas e serviços que objetivem promover a funcionalidade, relacionada à atividade e à participação da pessoa com deficiência ou com mobilidade reduzida, visando à sua autonomia, independência, qualidade de vida e inclusão social.

São exemplos de tecnologia assistiva as bengalas-guia, as cadeiras de rodas, os softwares leitores de tela, os aparelhos auditivos, os softwares acionáveis por movimentos do rosto, os cães-guia, as impressoras braille e tantos outros. Recursos direcionados exclusivamente à pessoa com deficiência, com respeito as suas especificidades, e que se associam à acessibilidade no alcance da maior autonomia e independência possíveis. Como exemplo, para uma pessoa com cegueira, o piso tátil será acessibilidade, enquanto a bengala-guia, o sapato com solado fino, o software de orientação no celular ou o cãoguia a tecnologia assistiva. $E$, assim, em espaços e serviços em que a acessibilidade e a tecnologia assistiva estão adequados e sincronizados, poucas ou nenhuma serão as limitações para o ir e vir de todos.

No entanto, para estimular e acelerar a existência de maior acessibilidade e tecnologia assistiva, ampliando e efetivando a inclusão social das pessoas com deficiência, foram instituídas as ações afirmativas. Estas, em especial, porque os estigmas e atitudes pessoais ainda são obstáculos à aproximação, interação e convívio com o sujeito com deficiência e com outras características ainda discriminadas, como a cor da pele, a etnia, a faixa etária e o gênero sexual, por exemplo. As ações afirmativas vêm com o objetivo de ampliar o acesso a oportunidades de inserção social, como à educação, o trabalho, o transporte e outros, estimulando a interação social e a quebra desses obstáculos mesmo que as condições para o ir e vir com autonomia e independência ainda não estejam contempladas.

No Estatuto da Igualdade Racial (Brasil, 2010, s/p), as ações afirmativas são entendidas como "os programas e medidas especiais adotados pelo Estado e pela iniciativa privada para a correção das desigualdades raciais e para a promoção da igualdade de oportunidades".

Embora o referido conceito direcione-as às desigualdades raciais, também pode ser concebido em prol dos excluídos por ocasião de limitações físicas, sensoriais e/ou intelectuais. E, nesse sentido, são exemplos de ações afirmativas: a reserva de vagas em 
concursos públicos e processos seletivos, as isenções de impostos na aquisição de órteses e próteses, o direito a passe-livre nos transportes públicos, o meio-ingresso em eventos culturais e esportivos, a reserva de vagas de trabalho em empresas privadas e outros. Em síntese, as ações afirmativas reconhecem as barreiras sociais existentes, algumas quem sabe intransponíveis até o momento, podendo-se citar as atitudinais em especial, e buscam estimular a interação social como uma forma de respeito à dignidade humana e o avanço das acessibilidades e tecnologias assistiva.

Então, acredita-se eliminar tais barreiras sociais por intermédio dessas políticas inclusivas em especial, leia-se as acessibilidades, as tecnologias assistiva e as ações afirmativas, além de outras com viés inclusivo e equânime.

\section{Educação inclusiva}

Estas políticas públicas são igualmente imprescindíveis no sistema educacional brasileiro para a ampla e devida inclusão de estudantes com deficiência. Tanto que, no segmento educacional, também é significativa a série de leis, normas, recomendações e outras diretrizes neste sentido: a lei n. 13.146/2015: Lei Brasileira de Inclusão da Pessoa com Deficiência (Brasil, 2015); decreto n. 6.949/2009: Convenção Internacional sobre os Direitos da Pessoa com Deficiência (Brasil, 2009); decreto n. 7.611/2011: Educação Especial e Atendimento Educacional Especializado (Brasil, 2011); decreto n. 5.296/2004: Prioridade de atendimento e promoção da acessibilidade para pessoas com deficiência (Brasil, 2004); lei n. 9.394/1996: diretrizes e bases da educação nacional (Brasil, 1996); lei n. 13.409/2016: reserva de vagas para pessoas com deficiência (Brasil, 2016).

\section{Quem são as pessoas com deficiência}

Imprescindível é caracterizar e identificar o público ao qual foram concebidas e destinadas estas políticas públicas e os recursos inclusivos, para o maior controle e garantia de suas efetividades e aplicações. O conceito de pessoa com deficiência vai exatamente nesse sentido, tendo sido atualizado na Lei Brasileira de Inclusão das Pessoas com Deficiência:

Considera-se pessoa com deficiência aquela que tem impedimento de longo prazo de natureza física, mental, intelectual ou sensorial, o qual, em interação com uma ou mais barreiras, pode obstruir sua participação plena e efetiva na sociedade em igualdade de condições com as demais pessoas. (Brasil, 2015, art. $2^{\circ}$ )

Ou seja, não apenas a condição pessoal determina a limitação, mas, também, as barreiras existentes e impostas na sociedade. Não mais o olhar apenas à pessoa com deficiência - perspectiva clínico -, destinando-lhe o estigma e a responsabilidade da limitação que possui, mas também para o seu entorno - perspectiva social - que critica as normas, práticas e costumes que foram instituídas com o desenvolvimento da sociedade, a partir de uma concepção de ser humano que também é questionável.

Por outro lado, é igualmente necessário e imprescindível um olhar avaliativo para as reais limitações resultantes da condição de deficiência diante dos obstáculos sociais existentes. E um olhar avaliativo para alcançar o público que necessita de políticas inclusivas de fato. Por isso, busca-se disseminar uma caracterização e avaliação mais ampla e justa das deficiências, com base em uma concepção biopsicossocial. Isto é, 
verificando-se até que ponto a limitação física, sensorial e/ou intelectual apresentada pelo sujeito resulta em limitações práticas importantes e que necessitem de acessibilidades e tecnologias assistiva para o ir e vir com autonomia, independência e segurança. Tal concepção é estruturada e organizada na Classificação Internacional de Funcionalidade, Incapacidade e Saúde:

A CIF é uma classificação com múltiplas finalidades elaborada para servir a várias disciplinas e sectores diferentes. Os seus objectivos específicos podem ser resumidos da seguinte maneira: proporcionar uma base científica para a compreensão e o estudo dos determinantes da saúde, dos resultados e das condições relacionadas com a saúde; estabelecer uma linguagem comum para a descrição da saúde e dos estados relacionados com a saúde, para melhorar a comunicação entre diferentes utilizadores, tais como, profissionais de saúde, investigadores, políticos e decisores e o público, incluindo pessoas com incapacidades; permitir a comparação de dados entre países, entre disciplinas relacionadas com os cuidados de saúde, entre serviços, e em diferentes momentos ao longo do tempo; proporcionar um esquema de codificação para sistemas de informação de saúde. (Organização Mundial da Saúde, 2004, p. 9)

Isso não significa que a Classificação Internacional de Doenças e Problemas Relacionados à Saúde tenha perdido sua função e importância na avaliação de pessoas com deficiência. Esse alerta encontra-se na própria CIF:

Nas classificações internacionais da OMS, os estados de saúde (doenças, perturbações, lesões, etc.) são classificados principalmente na CID-10 (abreviatura da Classificação Internacional de Doenças, Décima Revisão), que fornece uma estrutura de base etiológica. A funcionalidade e a incapacidade associados aos estados de saúde são classificados na CIF. Portanto, a CID-10 e a CIF são complementares, e os utilizadores são estimulados a usar em conjunto esses dois membros da família de classificações internacionais da OMS. (Organização Mundial da Saúde, 2004, p. 8)

De modo mais específico, exemplificam-se as importâncias e aplicações das políticas públicas inclusivas para as pessoas com deficiência visual. Estas possuem um conceito legal no Decreto Federal 3298/1999, atualizado pelo decreto n. 5.296/2004:

Deficiência visual: cegueira, na qual a acuidade visual é igual ou menor que 0,05 no melhor olho, com a melhor correção óptica; a baixa visão, que significa acuidade visual entre 0,3 e 0,05 no melhor olho, com a melhor correção óptica; os casos nos quais a somatória da medida do campo visual em ambos os olhos for igual ou menor que 60; ou a ocorrência simultânea de quaisquer das condições anteriores. (Brasil, 2004a, art. $2^{\circ}$ )

Neste conceito pode-se constatar o olhar unicamente clínico na avaliação da referida condição, sem contemplarem-se os aspectos da funcionalidade e da incapacidade adotadas pela CIF. Já em outro conceito, de pessoas com baixa visão, apresentado pela NBR 16.537:2016 (ABNT, 2016b), que trata de "diretrizes para a elaboração de projetos e instalação de sinalização tátil no piso", verifica-se um olhar mais abrangente e atento a estas questões. 
Baixa visão: acuidade visual entre 0,3 e 0,05 no melhor olho, com a melhor correção óptica ou somatório da medida do campo visual em ambos os olhos igual ou menor que $60^{\circ}$ ou a ocorrência simultânea de quaisquer das condições anteriores. Pessoas com baixa visão são aquelas que, mesmo usando óculos comuns ou lentes de contato ou implantes de lentes intraoculares, não conseguem ter uma visão nítida. Apresentam percepção de luz e resíduo visual para leitura e escrita ampliada. Segundo estimativa da OMS, cerca de $70 \%$ das pessoas com deficiência visual ainda possuem alguma visão residual aproveitável e passível de treinamento. As pessoas com baixa visão fazem uso da visão residual nas suas atividades diárias, inclusive para a sua locomoção. Este fato evidencia a necessidade do uso de luminâncias contrastantes na sinalização tátil no piso. (ABNT, 2016b, 3.2)

Mais adiante esta mesma norma técnica também apresenta uma sucinta, mas interessante referência e conceituação da bengala-guia, um instrumento que possivelmente signifique de modo mais representativo as potencialidades das pessoas com deficiência visual. Mas, por si só, esta conceituação enfatiza a importância de acessibilidades que se adequem a ela, a bengala-guia - uma tecnologia assistiva - e às especificidades dessa pessoa única que, dentre outras tantas características, possui deficiência visual. Conceitua-se bengala longa ou bengala-guia como: "recurso utilizado por pessoas com deficiência visual para locomoção, por meio de técnicas de rastreamento ou de varredura" (ABNT, 2016b, 3.3).

Convencionou-se que a bengala-guia para pessoas cegas deve ser branca. Atualmente esta convenção já não é tão seguida, mas cabe destacar-se que esta diferenciação ajuda na compreensão de quem é seu usuário e de maiores riscos ou acidentes principalmente no trânsito, permitindo que motoristas entendam que este não o pode ver a distância:

Para que o cego pudesse ser notado a tempo, era preciso começar por tornar a bengala mais visível: passou a ser branca. Quem teve essa ideia de longo alcance foi a condessa Guilly Herbemont, que em 1931 perante entidades públicas em Paris presenteou pessoas cegas com 100 bengalas brancas. (Deficiência visual, 2001, s/p)

As bengalas-guias também são políticas públicas inclusivas. Além de estarem previstas em leis e normas técnicas, também compõem programas nacionais de distribuição de órteses e próteses. Obviamente não se pode esquecer de outra tecnologia assistiva marcante para as pessoas com deficiência visual, o cão-guia: "animal castrado, isento de agressividade, de qualquer sexo, de porte adequado, treinado com o fim exclusivo de guiar pessoas com deficiência visual" (Brasil, 2005, art. $2^{\circ}$ ). Cães não conseguem diferenciar cores e, então, os semáforos sonoros tornam-se ainda mais necessários, além das pessoas com cegueira ou baixa-visão que utilizam bengalas-guia.

\section{Conclusão}

Saliente-se que as políticas públicas são desenvolvidas pela manifestação, articulação e força popular organizada, são revertidas ou adequadas, por vezes, da mesma forma, ou não. Estes aspectos da funcionalidade e da incapacidade apresentados pela CIF, tão importantes que, ignoradas em ações judiciais movidas por pessoas com visão monocular, permitiram-Ihes o acesso igualitário a políticas inclusivas, como as 
reservas de vagas em concursos públicos (Brasil, 1990, art. 5) ou empresas com cem ou mais trabalhadores (Brasil, 1991, art. 93), gerando uma competição incoerente contra as pessoas com cegueira ou baixa visão, público-alvo destas.

Quer dizer, sujeitos que conseguem ler apostilas, livros, sites, slides e tantos outros recursos de estudo sem qualquer dificuldade, além de cumprirem as provas por uma leitura e escrita sem a necessidade de qualquer adaptação, competindo para ocupar as mesmas vagas com candidatos que devem garimpar os textos para estudar - em braille, caracteres ampliados ou digitalizados para acesso via tecnologias assistiva -, além de necessitarem de mediações ou adaptações desgastantes e por vezes inadequadas para resolverem os testes.

"Os benefícios inerentes à Política Nacional para a Integração da Pessoa Portadora de Deficiência devem ser estendidos ao portador de visão monocular, que possui direito de concorrer, em concurso público, à vaga reservada aos deficientes" (Supremo Tribunal da Justiça, 2008, art. $\left.1^{\circ}\right)$. Quer dizer, tanto quanto superar a imagem da incapacidade, da inutilidade e da dependência que até hoje originam preconceitos das mais variadas ordens às pessoas com deficiência, também é muito importante esclarecer que não basta uma perda ou diferença física, sensorial e/ou intelectual para ter direito às políticas públicas inclusivas.

\section{Referências}

BRANKALEON, Brigida Batista; YAMANAKA, Jéssica Suzuki; CASTRO, José Marcelo de. Material didático para ensino a distância: disciplina de didática. São Paulo: USP, 2015.

BRASIL. Decreto n. 9.203, de 22 de novembro de 2017: dispõe sobre a política de governança da administração pública federal direta, autárquica e fundacional. Disponível em http://www.planalto.gov.br/ccivil 03/ ato2015-2018/2017/decreto/D9203.htm. Acesso em 31 mar. 2017.

BRASIL. Lei federal n. 13.409, de 28 de dezembro de 2016: altera a lei n. 12.711, de 29 de agosto de 2012, para dispor sobre a reserva de vagas para pessoas com deficiência nos cursos técnico de nível médio e superior das Instituições Federais de Ensino. Diário Oficial da República Federativa do Brasil, Brasília, DF, 28 dez. 2016. Disponível em http://www.planalto.gov.br/ccivil 03/ ato2015-2018/2016/lei/L13409.htm. Acesso em 16 jun. 2017.

BRASIL. Lei n. 13.146, de 6 de julho de 2015: institui a Lei Brasileira de Inclusão da Pessoa com Deficiência (Estatuto da Pessoa com Deficiência). Diário Oficial da República Federativa do Brasil, Brasília, DF, 6 jul. 2015. Disponível em http://www.planalto.gov.br/ccivil 03/ Ato2015-2018/2015/Lei/L13146.htm. Acesso em 15 abr. 2017.

BRASIL. Decreto n. 7.611 , de 17 de novembro de 2011: dispõe sobre a educação especial, o atendimento educacional especializado e dá outras providências. Diário Oficial da República Federativa do Brasil, Brasília, DF, 17 nov. 2011. Disponível em <http://www.planalto.gov.br/ccivil_03/_Ato2011-2014/2011/Decreto/D7611.htm. Acesso em $1^{\circ}$ maio 2017. 
BRASIL, 2010. Lei n. 12.288, de 20 de julho de 2010. Institui o Estatuto da Igualdade Racial; altera as Leis nos 7.716, de 5 de janeiro de 1989, 9.029, de 13 de abril de 1995, 7.347, de 24 de julho de 1985, e 10.778, de 24 de novembro de 2003.Diário Oficial da República Federativa do Brasil, Brasília, DF, 20 jul. 2010. Disponível em http://www.planalto.gov.br/ccivil 03/ Ato2007-2010/2010/Lei/L12288.htm. Acesso em 1은 maio 2017.

BRASIL, 2009. Decreto n. 6.949, de 25 de agosto de 2009. Promulga a Convenção Internacional sobre os Direitos das Pessoas com Deficiência e seu Protocolo Facultativo, assinados em Nova York, em 30 de março de 2007. Diário Oficial da República Federativa do Brasil, Brasília, DF, 25 ago. 2009. Disponível em http://www.planalto.gov.br/ccivil 03/ ato2007-2010/2009/decreto/d6949.htm. Acesso em 1을 2017.

BRASIL, 2006. Decreto n. 5.904, de 21 de setembro de 2006. Regulamenta a Lei no 11.126, de 27 de junho de 2005, que dispõe sobre o direito da pessoa com deficiência visual de ingressar e permanecer em ambientes de uso coletivo acompanhada de cãoguia e dá outras providências. Disponível em www.planalto.gov.br/ccivil 03/ ato20042006/2006/decreto/d5904.htm. Acesso em 18 mar. 2018.

BRASIL, 2004. Decreto n. 5.296, de 2 de dezembro de 2004. Regulamenta as leis $n$. 10.048 , de 8 de novembro de 2000, que dá prioridade de atendimento às pessoas que especifica, e 10.098, de 19 de dezembro de 2000, que estabelece normas gerais e critérios básicos para a promoção da acessibilidade das pessoas portadoras de deficiência ou com mobilidade reduzida, e dá outras providências. Diário Oficial da República Federativa do Brasil, Brasília, DF, 2 dez. 2004. Disponível em http://www.planalto.gov.br/ccivil 03/ ato2004-2006/2004/decreto/d5296.htm. Acesso em 15 abr. 2017.

BRASIL, 2002. Portaria n. 1060 / GM/MS, de 5 de junho de 2002. Política para a reabilitação da pessoa portadora de deficiência na sua capacidade funcional e desempenho humano, de modo a contribuir para a sua inclusão plena em todas as esferas da vida $\quad$ social. $\quad$ Disponível em http://dtr2001.saude.gov.br/sas/PORTARIAS/Port2002/Gm/GM-1060.htm. Acesso em 25 dez. 2017.

BRASIL, 1996. Lei n. 9.394, de 20 de dezembro de 1996. Estabelece as diretrizes e bases da educação nacional. Diário Oficial da República Federativa do Brasil, Brasília, 20 dez. 1996. Disponível em http://www.planalto.gov.br/ccivil 03/Leis/L9394.htm. Acesso em 1은 maio 2017.

BRASIL, 1989. Lei n. 7.834, de 6 de outubro de 1989. Cria a carreira e os respectivos cargos de especialistas em políticas públicas e gestão governamental, fixa os valores de seus vencimentos, e dá outras providências. Disponível em <http://www.planalto.gov.br/ccivil_03/leis/L7834.htm. Acesso em 31 mar. 2018.

DEFICIÊNCIA VISUAL. A bengala como símbolo e auxiliar. Die Gegenwart, n. 9, 2001. Disponível em http://www.deficienciavisual.pt/txt-bengala.htm. Acesso em 10 jul. 2018.

LANNA JÚNIOR, Mário Cléber Martins (comp.). História do movimento político das pessoas com deficiência no Brasil. Brasília: Secretaria de Direitos Humanos, 2010. Disponível em http://www.portalinclusivo.ce.gov.br/phocadownload/publicacoesdeficiente/historia\%20mo vimento\%20politico\%20pcd\%20brasil.pdf. Acesso em 10 abr. 2017. 
ORGANIZAÇÃO MUNDIAL DA SAÚDE. Classificação internacional de funcionalidade, incapacidade e saúde. Lisboa: Direção-Geral da Saúde, 2004. Disponível em http://www.inr.pt/uploads/docs/cif/CIF port \%202004.pdf. Acesso em 18 set.2018

SASSAKI, Romeu Kazumi. Nada sobre nós, sem nós: da integração à inclusão. Revista Nacional de Reabilitação, ano X, n. 57, 2007, p. 8-16.

SUPREMO TRIBUNAL DA JUSTIÇA-STJ, 2008. Nova súmula: visão monocular é razão para concorrer em vaga de deficiente. Disponível em http://dj.stj.jus.br/20150422.pdf. Acesso em 16 set. 2018.

Cristian Evandro Sehnem é pedagogo e assistente em administração na Universidade Federal de Santa Maria.

Orcid: https://orcid.org/0000-0001-7539-8437.

Endereço: Avenida Roraima, 1000 - 97105-900 - Santa Maria - RS - Brasil.

E-mail: cristiansehnem@gmail.com.

Silvia Maria de Oliveira Pavão é professora no Departamento de Fundamentos da Educação da Universidade Federal de Santa Maria.

Orcid: https://orcid.org/0000-0002-5365-0280.

Endereço: Rua Portugal, 199 - 97030-490 - Santa Maria - RS - Brasil.

E-mail: silviamariapavao@gmail.com.

Recebido em 30 de setembro de 2018.

Aceito em 22 de dezembro de 2018.

(c) (i) 